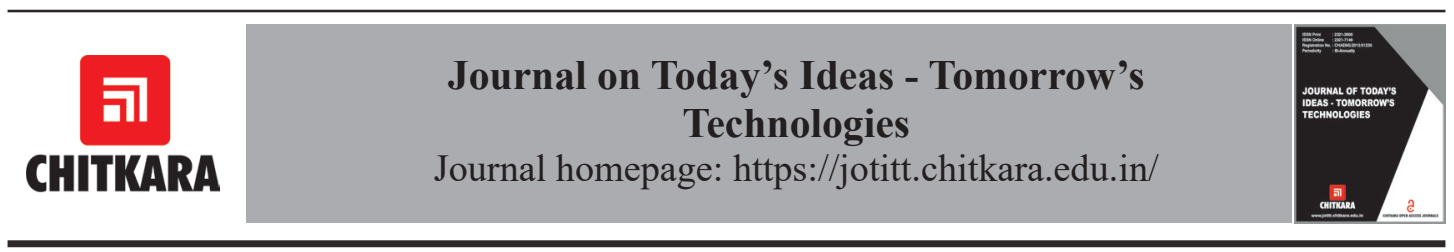

\title{
Automated Sanitization Device - Hand Sanitization, Thermal Screening and IoT-based Web-database
}

\author{
Prathamesh Samal*, Sutirtha Roy, Akash Chauhan, Vishu Chauhan, Vaibhav Malhotra, Shivam \\ Pundir, Swatantra Singh and Jatin Kanojia
}

Thapar Institute of Engineering and Technology, Prem Nagar, Patiala, Punjab-147004, India

Email: samalprathamesh123@gmail.com*

\begin{tabular}{|c|c|}
\hline ARTICLE INFORMATION & ABSTRACT \\
\hline $\begin{array}{l}\text { Received: June 11, } 2020 \\
\text { Revised: June 20, } 2020 \\
\text { Accepted: June 26, } 2020 \\
\text { Published online: December 03, } 2020\end{array}$ & $\begin{array}{l}\text { In this time of great distress brought about by the COVID-19 pandemic, hand } \\
\text { sanitization is of utmost priority to prevent the transmission of germs. We have } \\
\text { come forth with an innovative "automated sanitization device" which makes the } \\
\text { process of hand sanitization and temperature screening rapid, automatic and easier. } \\
\text { The proposed automated sanitization device contributes significantly to prevent the } \\
\text { spread of the virus and also raises awareness to increase hygiene at public places. }\end{array}$ \\
\hline $\begin{array}{l}\text { Keywords: } \\
\text { Hand hygiene, Sanitization, } \\
\text { Temperature screening, Contact-less } \\
\text { technology, Internet of Things (IoT) }\end{array}$ & $\begin{array}{l}\text { The concept of embedded systems with various sensors attached to a PCB has been } \\
\text { used in designing of the device. This paper addresses the methodological details } \\
\text { of proposed automated sanitization device while focusing on its technical as well } \\
\text { as financial expects. The proposed device is anticipated to be used at various public } \\
\text { places like workplaces, residences, railway stations etc. working of this model, } \\
\text { addressing both the technical as well as the financial aspect. }\end{array}$ \\
\hline
\end{tabular}

DOI: $10.15415 /$ jotitt.2020.81005

\section{Introduction}

Recently the rapid spread of COVID-19 worldwide, a highly infectious disease with high death toll, demands the need for maintaining proper hygiene atthe public places. Hand hygiene is regarded as one of the most important elements of infection control activities [1]. Hand hygiene compliance is boosted when convenient and readily accessible dispensers are installed [2]. In many places conventional methods like using bottled sanitizers to dispense sanitizer manually and hand held temperature scanners make this process risky as there are chances of cross-contamination because the process is manual and involves human intervention. Recent studies indicate that electronic devices can play an important role in hand hygiene compliance. The research identified compliance improvement from 36.3 percent at baseline to 70.1 percent during the second phase of the study at a 30-bed academic medical centre haematology unit [3].

The advancement of contact-less technology further creates an even more sterile environment. Using contact-based devices pose a wide risk of cross-contamination, hence devices with touch-less features need to be developed and implemented to contain the spread of the virus. The existing touch-less technology helps facilitate infection prevention but has limited 
features [4]. There is a dire need to develop a device which can integrate multiple features like automatic hand sanitization, contact-less temperature screening and data storage of suspected infection carriers in a server. The automated sanitization device integrates all these features and makes the process of sanitization rapid and easier.

There are many similar devices available in the market which include mini kiosks, automatic sanitizer dispensers which can perform automatic hand sanitization and contact-less temperature screening [5].

Recently Defence Research and Development Organization (DRDO) developed a Contactless Sanitizer Dispenser which is an automatic mist-based dispenser for optimizing the sanitizer usage [6]. It is an excellent solution for large scale sanitization of people entering a premise.

The proposed IOT enabled device has a web-based database which facilitates the transfer of details of people with high temperatures to health department authorities. The data stored in the server notifies the health authorities and police to intervene or take action on the sick person. This system will prevent the entry of suspect cases to public places andwill also be helpful for contact tracing which will eventually improve the prevention of infection spread.

The proposed automated sanitization device has following features:

(i) Low cost device INR 8500/-

(ii) Capacity of handling masses

(iii) Compatible - small size, portable and easy to mount

(iv) Contact-less use

(v) Rapid Use - quick pass-through, entire process takes only 10 seconds per person. The proposed device is anticipated to increase awareness of hygiene at public places at low expenditure. This paper is divided as follows: section 2 brings forth the methodological details of proposed automated sanitization device. All the results obtained using proposed device have been described in section 3 . The important conclusions obtained from this work have been discussed in section 4 .

\section{Methodology}

This section brings forth the adopted methodology to design proposed automated sanitization device. The functioning of the device is based on the concept of embedded systems. Arduino Pro Mini microcontroller has been used for the overall functioning of the device. Various sensors are connected to Arduino in order to fulfil the circuit requirements.

Table 1: Components used in the automated sanitization device [5]

\begin{tabular}{|l|l|l|}
\hline Component Used & Specification & $\begin{array}{l}\text { Cost } \\
\text { (INR) }\end{array}$ \\
\hline Arduino Pro Mini (1) & $5 \mathrm{~V} / 16 \mathrm{MHz}$ & 300 \\
\hline Ultrasonic Sensor (1) & $5 \mathrm{~V}$ & 100 \\
\hline OLED Display (1) & $5 \mathrm{~V}, 1.3$ Inch & 350 \\
\hline DC Pump (1) & $\begin{array}{l}12 \mathrm{~V} \text { DC, Flow Rate: } \\
24 \mathrm{~L} / \mathrm{H}\end{array}$ & 300 \\
\hline Temperature Module (1) & $5 \mathrm{~V}$, High Accuracy & 2000 \\
\hline LED \& Buzzer (1) & Alerting Purpose & 50 \\
\hline Frame & $\begin{array}{l}3 \mathrm{D} \text { Printed / } \\
\text { Metallic Body }\end{array}$ & 900 \\
\hline Printed Circuit Board & $\begin{array}{l}\text { All the components } \\
\text { will be embedded in } \\
\text { the PCB }\end{array}$ & 500 \\
\hline Node MCU (1) & $\begin{array}{l}\text { Wireless Data } \\
\text { Transfer }\end{array}$ & 300 \\
\hline Miscellaneous & Assembling Cost & 200 \\
\hline Total & a & $\mathbf{5 0 0 0}$ \\
\hline
\end{tabular}

The working of the device is made completely automatic after making a circuit and embedding various components mentioned in the table 1 into a PCB/Perf-board and programming the Arduino as well as NodeMCU accordingly. The programming is done using a high-level language $\mathrm{C}++$. The circuit diagrams for the contactless temperature screening and automatic sanitizer dispensing system have been depicted in Fig. 1 and Fig. 2 respectively. 


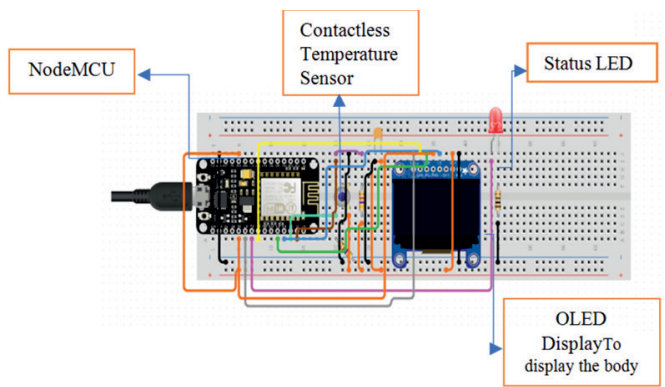

Figure 1: Circuit diagram for contactless temperature screening

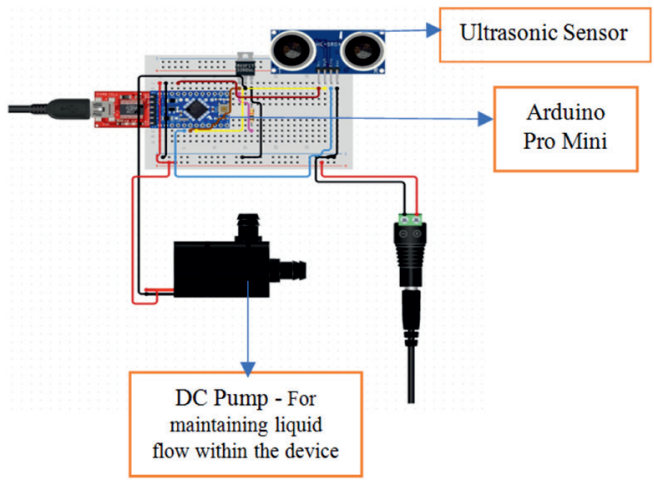

Figure 2: Circuit diagram for automatic sanitizer dispensing system

When a person arrives at the place where this device is installed, it automatically begins sanitization procedure. The device starts dispensing 5-6 $\mathrm{ml}$ of alcohol-based sanitizer as soon as the hands of a person are detected in close proximity with the device using the ultrasonic sensors. Further, the contact-less temperature screening of the person is carried out using MLX90164 IR Thermometer which measures the body temperature without any contact. If a person with high temperature is detected, an alarm along with alert lights is activated. The individuals with high temperature may be a potential COVID-19 infection carrier and hence the details of such individuals must be stored as well as shared with the health department as a precautionary measure so that they can be tracked easily. The stored detailswill be beneficial for contact tracing purposes as well. All the details will be transferred to thedatabase using IoT using Node MCU. The model for proposed device is shown in Fig. 3.

The data of the people with high temperature can be retrieved using a website wherein the attendant/guard present at the entry point can input the data to the website via smartphone. Another way of data retrieval of such highrisk individuals can be done using a bar code scanner, which is compatible with most of the ID cards, Aadhaar Cards etc. These are the two contact-less detail retrieval methods that can be used to get the details of the people with high temperature. The process has been summarized using a flowchart in Fig. 4.
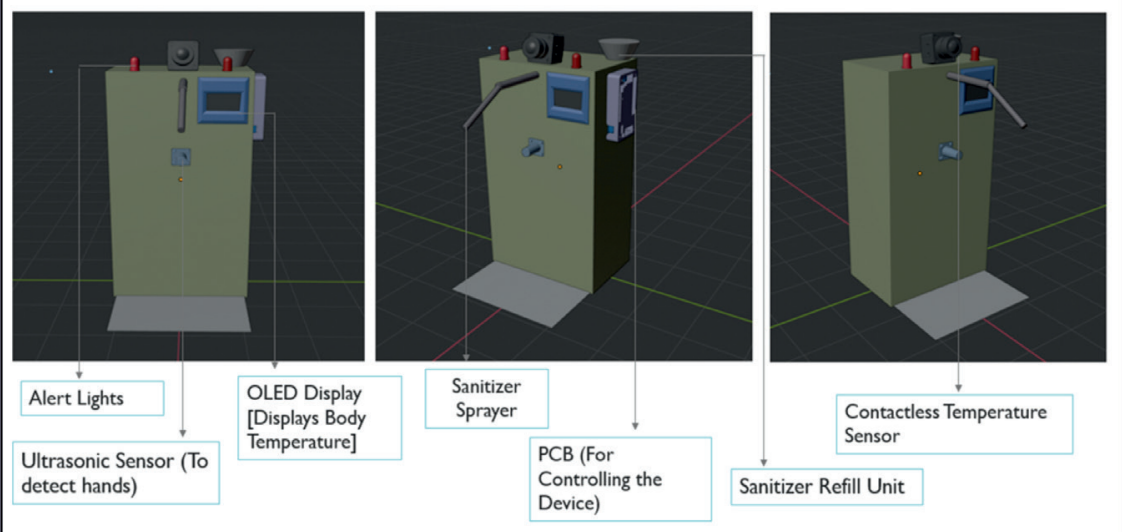

Figure 3: 3D Device Model 


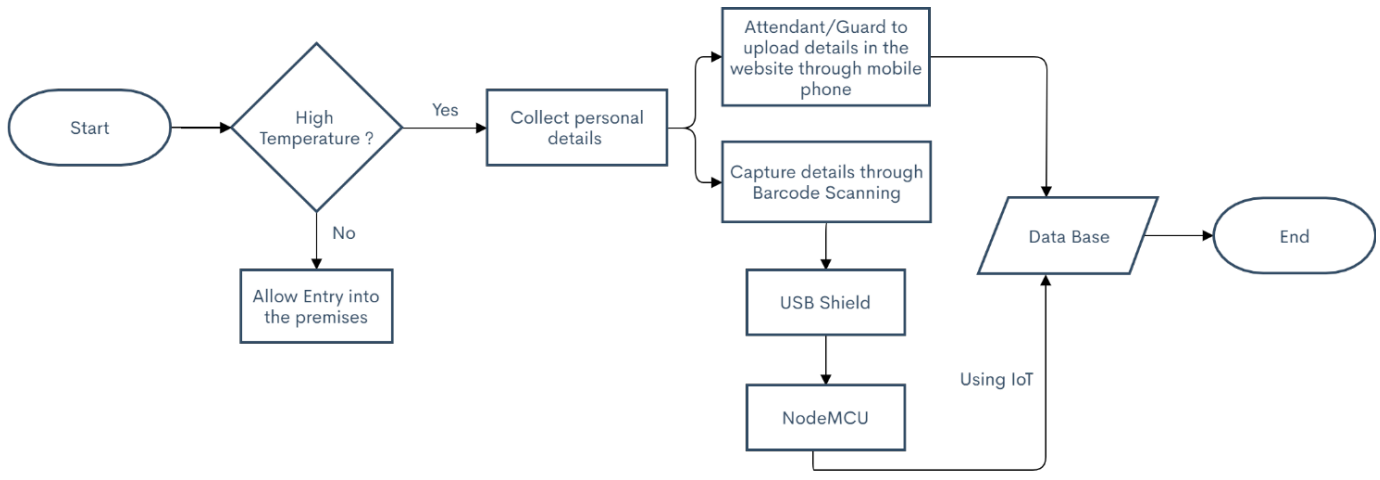

Figure 4: Flowchart for data entry of details of high-risk individuals

\section{Results and Discussion}

This section describes important results obtained for proposed automated sinitization device. The proposed device makes the entire process of sanitization rapid, easier and cost effective. The overall cost of sanitization of a person costs only INR $0.66 /$ person/year. The low cost of sanitization is insignificant compared to high cost of infection, spread, treatment and diverse socio-economic impact. The cost to customer of the device is mentioned in Fig. 5.

The device has a 3 Litres sanitizer tank which dispenses $5 \mathrm{ml}$ of sanitizer per person. It has been assumed that the sanitizer is refilled once every day. Based on the assumption for one device certain facts have been mentioned follows:

(i) Number of people sanitized per day: 600

(ii) Number of people sanitized per year: 2,16,000 (18,000 people screened per month)

(iii) Cost of sanitizer: INR 12,000/Month (INR 400 per day for $3 \mathrm{~L}$ of sanitizer) (iv) Yearly cost of sanitizer: INR 1,44,000

(v) Cost of sanitization: yearly cost of sanitizer/No. of people screened per year $=$ INR 0.66

The approximate cost of sanitization is INR 0.66/person which proves that the device has a low operational cost. This system will prevent entry of suspect cases to public areas and also track their movement, so authorities can trace the non-compliant individual. The overall process gets simplified by using the automated sanitization device. The simplified process is depicted in Fig. 6.

One unique feature of this device which makes it unique amongst other existing devices is its low cost. A brief cost structure for the device is given below:

1. Total Component Cost: INR 5000 (refer

Table 1)

2. Barcode Scanner: INR 1500

3. Assembling Charges: INR 500

4. Device Installation Cost: INR 300

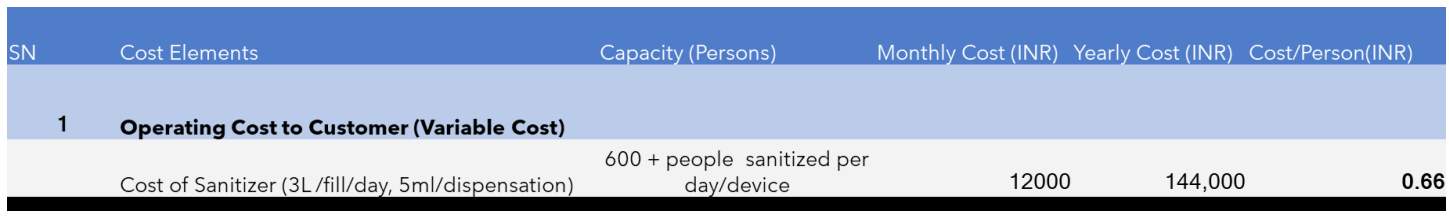

Figure 5: Cost to customer of the device 


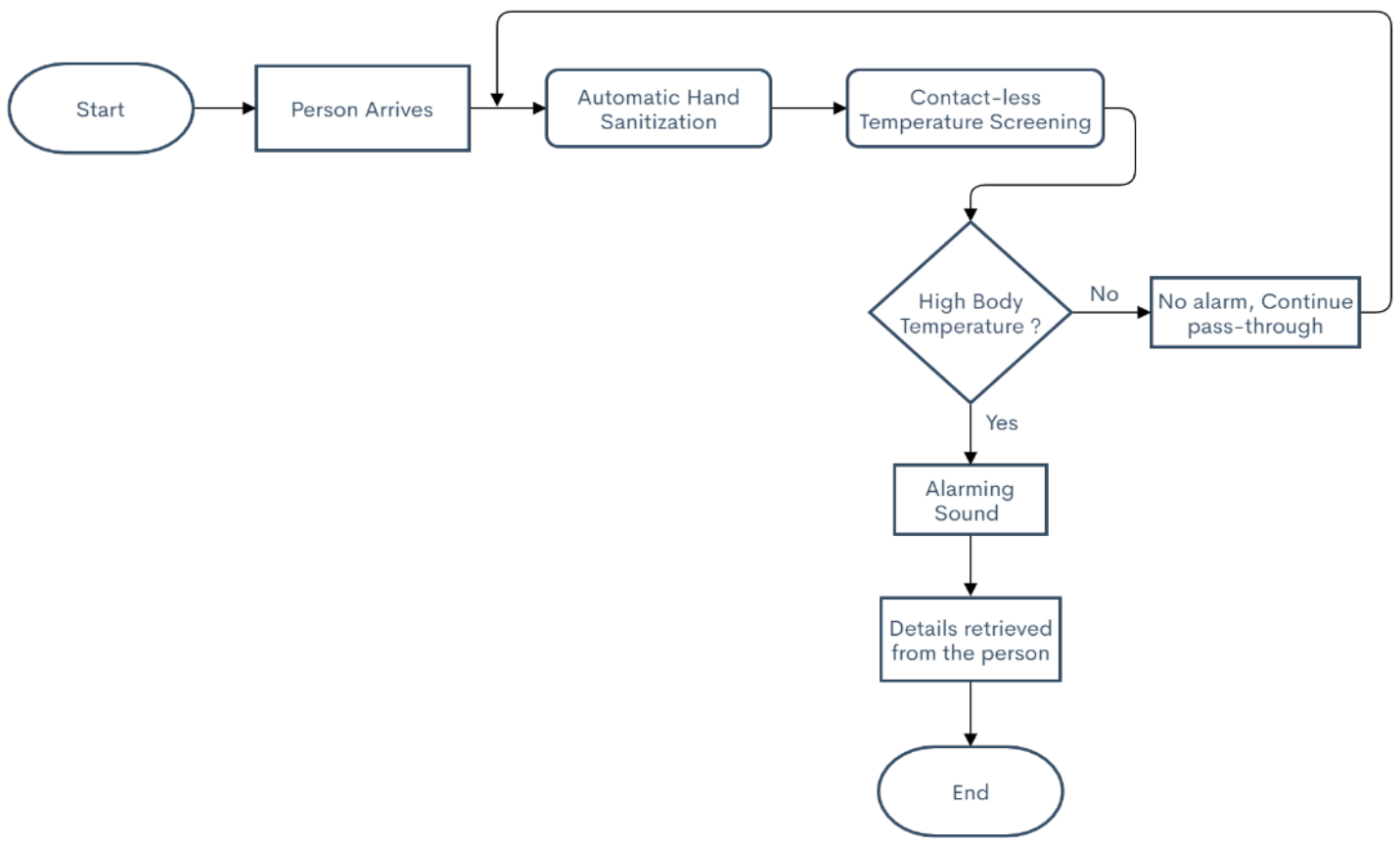

Figure 6: Flowchart for the sanitization process

5. Transportation Cost: INR 200 (PanIndia)

6. Taxes: INR 1000 (approx.)

7. Device Cost: INR 8500

The approximate cost of the device is INR $8500 /$ - There is a huge potential for a price uplift depending upon the market demand. Since there is a website which needs to be hosted for maintaining a database of highrisk individuals an extra cost of INR 1500/ year is applicable. This includes website domain and hosting charges.

The device's compatibility with most of the public places makes it a highly scalable model to implement. This device is not location specific and can be installed anywhere where proper hygiene needs to be maintained. The reasons for its compatibility that its small size [Dimensions: $35 \mathrm{~cm}(\mathrm{~h}) \mathrm{X}$
$25 \mathrm{~cm}(\mathrm{w}) \mathrm{X} 20 \mathrm{~cm}(\mathrm{~d})]$, can be easily mounted anywhere and doesn't require much human interference for its regular functioning. It takes approximately 10 seconds for the entire process per person and can screen and sanitize 600 people in one refill which makes the pass-through rapid. Multiple such devices can be installed at places where there is higher public mobility, for example railway, metro, bus stations etc. By using this device, the goal for increased sanitation at public places can be achieved. The comprehensive and smart features which come along with the device lead to a fast-paced precautionary procedure which can lower the chances of infection spread significantly. The complete sanitization process has been given in the flowchart as shown in Fig.7. 


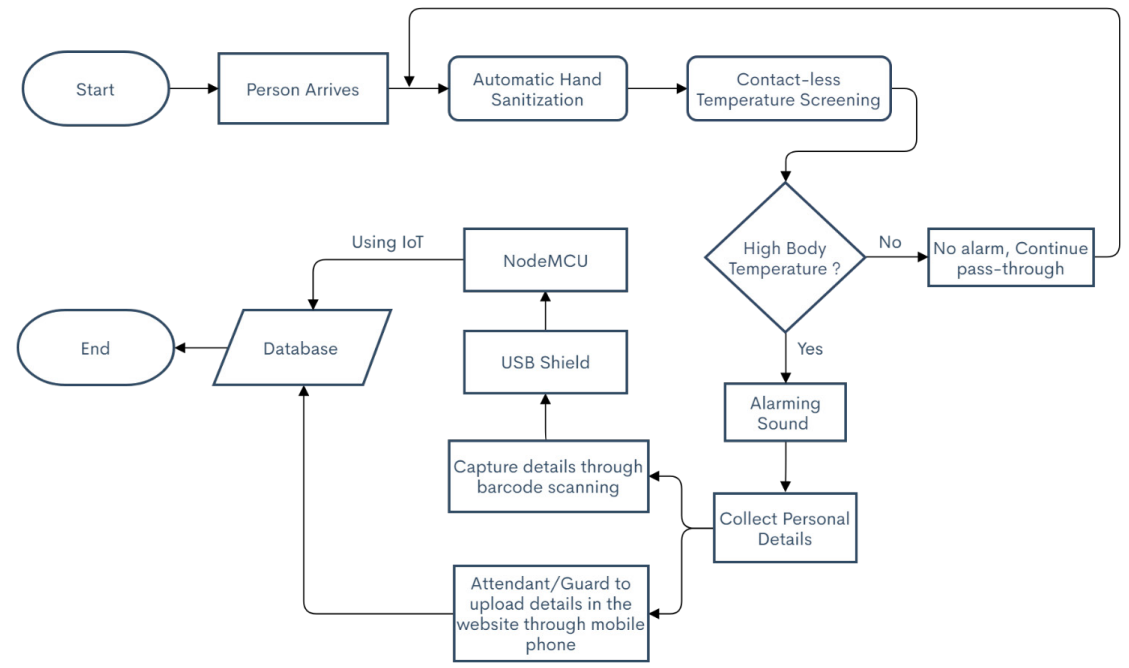

Figure 7: Flowchart for the complete sanitization process

A brief outline of the website which will be used for retrieving data of high-risk people has been given in Fig. 8. This will be beneficial to keep a record of high-risk individuals. Multiple such devices can be installed at places where there is higher public mobility, for example railway, metro, bus stations etc. By using this device, the goal for increased sanitation at public places can be achieved.

\section{Conclusion}

The market for touch-less technology-based devices is emerging rapidly. There is an urgent

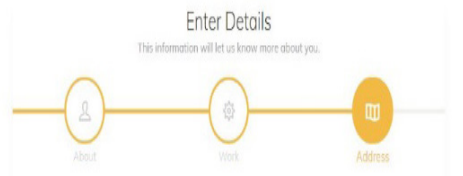

Flease intiom us about your location.
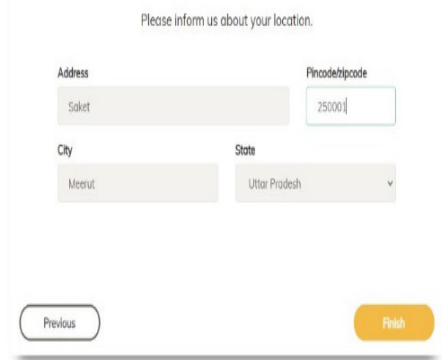

need of sanitizing devices with minimal or no contact to prevent transmission of germs from an infected to a healthy person. By using the automated sanitization device, required hygiene compliances can be ensured and this device will also encourage hand hygiene, which will eventually lower infection spread as well as prevent the entry of suspect cases to public areas by alerting the authorities during the contact-less temperature screening. The proposed device can be extremely useful for complying with good hygiene standards at public places like busstations, railway-stations etc.
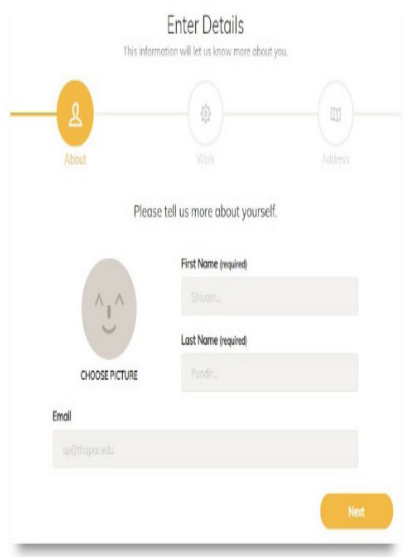

Figure 8: Self-designed website for data retrieval of people with high temperature 


\section{References}

[1] M. Purva. Hand hygiene: Back to the basics of infection control. Indian Journal of Medical Research, vol. 134, no. 5, pp. 611-620, 2011.

[2] R. Girard, K. Amazian, J. Fabry. Better compliance and better tolerance in relation to a well-conducted introduction to rubin hand disinfection. Journal of Hospital Infection, vol. 47, pp. 131-137, 2001. https://doi.org/10.1053/jhin.2000.0854

[3] A. K. Venkatesh, M. G.Lankford,D. M. Rooney, T. Blachford, C. M. Watts, \& G. A. Noskin. Use of electronic alerts to enhance hand hygiene compliance and decrease transmission of vancomycin-resistant enterococcus in a hematology unit. American Journal of Infection Control, vol. 36, no. 3, pp.199-205, 2008. https://doi.org/10.1016/j.ajic.2007.11.005
[4] S. K. Nichols. Touchless technology helps facilitate infection prevention best practices. Infection Control Today, 2007.

[5] Indiamart. Automatic Hand Sanitizer Dispenser. [Online] Available: https://www.indiamart. $\mathrm{com} /$ proddetail/automatic-hand-sanitizerdispenser-22294122891.html [Accessed: 25 May, 2020]

[6] DRDO. Contactless Sanitizer Dispenser (CSD) developed by DRDO-CFEES. [Online] Available: https://www.drdo. gov.in/video-gallery/contactless-sanitizerdispenser-csd-developed-drdo-cfees [Accessed: 25 May, 2020]

This article has been published as a part of Special regular issue of Journal on Today's Ideas Tomorrow's Technologies. Most of the articles in this issue are the papers for which the original ideas were presented at NOVATE 2020 (https://www.chitkara.edu.in/novate), a competition organized by Chitkara University and supported by Ministry of Electronics and Information Technology, Govt. Of India, Institution's Innovation Council, NSTEDB, Govt. Of India and FICCI. Student participants have written most of these articles. Some basic editing work has been done at the editorial level, but same have not been corrected very rigorously so as to preserve basic touch of student's writing.

\title{
旬 CHITKARA
}

\author{
Journal on Today's Ideas - Tomorrow's Technologies
}

Chitkara University, Saraswati Kendra, SCO 160-161, Sector 9-C, Chandigarh, 160009, India

Volume -8, Issue-1

June 2020

ISSN 2321-3906

Copyright: [C 2020 Prathamesh Samal et al.] This is an Open Access article published in Journal on Today's Ideas - Tomorrow's Technologies by Chitkara University Publications. It is published with a Creative Commons Attribution- CC-BY 4.0 International License. This license permits unrestricted use, distribution, and reproduction in any medium, provided the original author and source are credited. 